\title{
The Artistic Design of Chinese Film and Television Animation Characters - The Aesthetics of Semiotic and Realistic Re-creation
}

\author{
Jingjun $\mathrm{Xu}^{1, *}$ \\ ${ }^{1}$ Sichuan Fine Arts Institute, Chongqing 401331, China \\ *Corresponding author. Email: 390539573@qq.com
}

\begin{abstract}
In recent years, Chinese film and animation has grown to a large number, and all major children's channels broadcast a variety of low-age cartoons every day. The emergence of a variety of high-quality Chinese film animation in recent years has also shown people that Chinese film and animation is slowly reviving. From these films, it can be seen that the artistic design of Chinese film and animation characters has its own characteristics, and on the basis of people's original impressions, the reconstruction of the inner quality is carried out in an innovative way, which not only enriches the connotation of the characters, but also realizes a new interpretation of the aesthetics of reconstruction from the perspective of semiotics and realism. This is the core of the revival of Chinese film and animation. This thesis will start from the artistic design of the characters of Chinese film and television animation, and discuss the aesthetics of semiotic and realistic reconstruction in detail through the explanation of several Chinese film and television animations.
\end{abstract}

Keywords: Chinese film and television animation, Artistic design of characters, Semiotics, Realism, Reconstructive aesthetics.

\section{INTRODUCTION}

Film and television animation is a comprehensive art, collecting the characteristics of film and television audiovisual as well as covering the artistic characteristics of many art disciplines such as comics and literature. The expressiveness of these different artistic features is reflected in the character image of animation, which constitutes an aesthetic and cultural value different from the traditional single art form. In this regard, the character image of film and television animation belongs to the most important part of the content of film and television animation, and is also the most indispensable symbol in film and television animation. Therefore, the image of film and television animation works as the most powerful medium of cultural communication in film and

*Project: Research on technological innovation and application of panda Digital Cultural industries (Project No. kjcx 2020042), a scientific and technological innovation project of "construction of Chengdu and Chongqing double City Economic Circle" of Chongqing Municipal Education Commission television animation works. Through its unique artistic language and under the control of the communicator, the image fully carries and conveys a variety of established content, playing the role of a carrier to promote cultural communication and transmutation, and becoming a unique symbol of cultural layer rich in realism. On the other hand, in terms of its commercial symbolic function, the successful transformation of film and television animation image as a commercial symbol is based on its cultural symbolic function, but its cultural mission must be realized and maintained through commercial means. Therefore, it needs to be interpreted with a new aesthetics in the middle of semiotics and realism, so that it not only serves as the most core relationship of film and television animation communication, but also reflects that to reflect the central idea which film and television animations really want to spread is also a unique medium. 


\section{SEMIOTICS AND CHARACTER DESIGN FOR FILM AND ANIMATION}

In a film and animation work, the design of character image is the core, and it carries the soul of the work. Animation character image is a symbolic language, and it has an important symbolic meaning. For example, when it comes to Black Cat Sheriff, people think of justice, bravery and wit; when it comes to Porky Pig, it is lazy and timid; when it comes to Pleasant Goat, it is smart, friendly and kind. There is a symbolic relationship between the image of animation characters and the cultural characteristics of the works. The character image of animation exists in the form of symbols, or it is a collection of cultural traits symbolized.

Today, China is in a phase of deep transformation in the field of animation, and a clear goal has been seen to achieve a real renaissance, so the creation of the Chinese film and animation image is no longer a mere cartoon image, but the cultural connotation which will be the soul of the character. The meaning of the animated image depends precisely on the symbolic meaning, in other words, the cultural value of the character.

In his treatise on semiotic aesthetics, Roland Barthes suggests that "in the contemporary form of aesthetics and literature, it is difficult to grasp the different aspects of art without the semiotics of art language and its communication, without the study of the special role of symbols in art and the interrelationship between symbols and meaning in creation, and without the revelation of the dual structure of symbols in various cultural systems. It is difficult to grasp the laws of art creation and appreciation, of linguistic and non-linguistic phenomena from different aspects without the study of the special role of symbols in art or the interrelation of symbols and meanings in creation, and without the revelation of the dual structure of symbols in various cultural systems. Each artistic expression constitutes a symbolic system of specific meanings. In this sense, the study of symbolic analysis is indispensable for aesthetics and art theory."

For example, the "The Monkey King", as early as the 1960s, was interpreted in a new and righteous way in the form of " The Monkey King ", and after that, through the continuous performance of TV and movies, it has long formed a fixed role image in people's mind, which is, a role symbol, and in the process of continuous dissemination, it has been endowed within the process of continuous dissemination. Additionally, it has been given a deep connotation and cultural qualities. However, the animated movie "The Return of the Great Sage" has a new perspective on its interpretation of justice, so that people feel refreshing when they see it, and at the same time, there is more online and offline constant exclamation: the return of the Great Sage ... This is where the value of semiotics lies.

Thus, in this respect, the value of semiotics is that it places the simple animated characters in a broader cultural context, thus making the social value of animation creation get a boost. The semiotic study of film is not a distillation of the abstract film grammar, but an open symbolic system for reality and audience. Under the crosscultural perspective, each film can be seen as a cultural text, and each image symbol is a carrier of a certain culture, and the director will inevitably inject a certain cultural element into each image symbol in the process of using the image symbol to express.

\section{REALISM AND CHARACTER DESIGN FOR FILM AND ANIMATION}

In the process of production and dissemination of film and television animation, there is another inescapable point - realism, and the most realistic in film and television animation is the role in animation. Therefore, film and television animation character design, no matter in adult animation, or in children's animation, contains the quality of realism to some extent, which is inevitable.

For example, in reality, young parents are constantly busy with working and making money from day to night. When they go back home, they have been exhausted, so reasonably in the education of their growing-up children, they may slacken. If it continues for a long time, it will make the next generation grow up crooked, thus making society more complicated. At this time, many films and animations are based on this realism to produce the role. Through the character in the animation story behavior, these films and animations want to teach the growing children tell the right from the wrong. A good example is the film and animation "Confucius".

At the beginning of the film, one does not see the image of the old man with white hair and a stooped figure seen in the scroll. Instead, it is an image of a young Confucius with his hair in a bun 
and dressed in brown rough linen. Through the surrounding environment and Confucius' dress, the realistic situation of Confucius' poor family when he was young is restored, showing the image of a good young man who is still diligent and studious in a difficult environment and is not ashamed to ask questions, which helps to educate today's children and youth. Then comes the image of a young Confucius with firm eyes, dressed in a green shirt, studying and discussing with others, mainly highlighting his character and excellent qualities. The last appearance is the image of Confucius in his middle and old age. At this time, Confucius already appears to be calm and dignified, with his eyes revealing a grave and solemn look, and his hands and feet show his ritual and elegance.

On the whole, this phased presentation of Confucius makes the character development clearer, and the appearance of the young Confucius can, without any doubt, quickly and effectively attract the attention of children and teenagers. Imagine that the opening of the animation is an old man talking about profound and obscure political ideas. I am afraid that few children are willing to continue to watch. This is the cleverness of the film's storyline, which allows children to witness the growth of Confucius or grow up with the animated characters to help them love and understand the characters. Character costumes and props are also designed according to the age of the character and the environment. For example, teenage Confucius is dressed in sackcloth, and a relatively high rate of appearance props is a book. The costume of Confucius in his middle and old age is a broad-robed and large-sleeved dafu dress, which looks mature and sophisticated. These are based on the character setting in the context of the era and the role setting. The color selection is also in line with the theme and with the persona.

As a large historical theme of the cartoon, its plot is set based on the life of Confucius, such as traveling around the world, gathering to lecture and other familiar historical stories. Although it is an ancient scenario, it has a very strong realism features, which makes the animation plot vivid and interesting, with the fate of the characters ups and downs. The rhythm of relaxation, as well as the natural and clever narrative, is a good education for children. At the same time, it arouses their interest in watching and thus fulfills the responsibility of spreading the artistic role of film and animation. And from the movie Confucius, we can also find that film and animation are in the process of public screening. It is inevitable that it naturally carries the characteristics of realism.

\section{RE-CREATIVE AESTHETICS AND CHARACTER DESIGN FOR FILM AND ANIMATION}

People who like film and television animation have seen countless animation films. Especially in recent years, they will find a phenomenon that whether it is newly created film and television animation, or in Chinese mythology or historical stories based on the new interpretation of film and television animation, its role design has a unique aesthetics. This aesthetics is not uniform, but without losing the Chinese cultural characteristics on the basis of imagination, through the reality of people or events recreated and rich in very distinctive characteristics. This characteristic has both the shadow of people's impression and a great difference, thus bringing everyone endless joy and comprehension. This is the process of film and television animation character design, in the semiotics and realism based on the formation of the unique phenomenon of re-creation of aesthetics.

For example, the recreated aesthetics of character design in " Monkey King: Hero Is Back " is very clear. The Monkey King is no longer the image of the TV series that people remember as the unity of man and god, nor the dramatic image in "The Monkey King", but a more exaggerated image formed on the basis of animals, with more humanlike behavior. This exaggerated image did not make people feel uncomfortable or disgusted, but had a very powerful communication effect and became another classic image of The Monkey King soon after the movie was broadcast, which is where the power of the aesthetics of recreated sex lies. In " Monkey King: Hero Is Back ", apart from the wellknown Monkey King, there is also the image of the young Tang Monk, who is also influenced by different experiences before and after the story and has different comprehensions, which makes him change constantly, thus making the character image appear more three-dimensional and also more powerful in terms of recreated aesthetics.

In addition to " Monkey King: Hero Is Back," Nezha, Ao Bing, Shen Gong Bao and Tai Yi Zhen in "Nezha" also show their unique aesthetic characteristics with different character art designs. This aesthetic feature is different from the established images that people have fixed in the past, but redesigned according to people's preferences and the needs of the story. This is 
where the recreated aesthetics are relevant, so that people can watch the movie and also look at the inner beauty of the character art design level with an appreciative mindset. In addition to the above well-known animated movies, there are also "Lanting Pixie", which shapes the seven stroke sprites of dot, horizontal, apostrophe, down, vertical, fold and hook, bringing people a new sense of beauty of word comparison; " White Snake ", which shapes the image of the lovely and lively White Snake, breaks the artistic image of the adult version of White Snake love; " Legend of Deification ", which shapes the image of the young Jiang Ziya who dares to brave difficulties, breaks the artistic image of the white haired old man that people think of.

If people watch the above films and taste carefully, they will find that the artistic image of each character in film and animation is a new aesthetic performance, a recreated aesthetics based on semiotics and realism, which enriches people's visual enjoyment while bringing everyone a classic artistic image imprint, thus becoming a bright landscape in Chinese film and animation.

\section{CONCLUSION}

Through the above analysis, it can be seen that the character art design in Chinese film and television animation, firstly, is to establish the character symbol through the story content, making it a unique existence in semiotics and becoming an important part of film and television animation. Secondly, the story content gives the character a clear view of the character, making it a character with rich realism for rich interpretation. Again, according to the character characteristics, the content of the story, as well as reference to the aesthetic needs of the public and social reality, the aesthetics of the re-creation, step by step, transformed into a cultural brand image from a separate character art image. Then, it steps into people's vision, through the way of propaganda broadcast, so that people get to enjoy and get a different degree of understanding and growth.

Nowadays, the film and television animation production company gradually develops from the beginning to the mature stage, which can rely on the local cultural resources. These companies develop animation subjects with different characteristics, and gradually establish the cultural brand image in the process of cultural reproduction. Such a model has become an important operation mode in the animation industry now. Extending the value of excellent animation works can not only extend the "life" of its works, but also increase the economic added value, produce more far-reaching influence, and realize the value of cultural communication. In this process, the value of animation characters will be developed to the maximum, so that they can be known and loved by more people.

\section{AUTHORS' CONTRIBUTIONS}

This paper is independently completed by Jingjun $\mathrm{Xu}$.

\section{REFERENCES}

[1] [US] Wendy Jane Hansen: Screenwriting: Step by Step, Beijing, World Book Publishing Company Beijing, 2010.

[2] Tang Jie: "Chinese animated films under film semiotics - Taking Big Fish Begonia as an example", in Brand Research, 2018(04).

[3] Mi Gao Feng, Zhang Yichuan, "Animation character symbolization: destructive reconstruction and strangeness carnival taking "100,000 cold jokes" as an example", in Art Review, 2015(09).

[4] Zheng Yang. Legend of Deification: an adult fairy tale that fits the temperament of contemporary society [N]. China Art Newspaper, 2020-10-14(009).

[5] Zhang Xiaohuan. Legend of Deification: the rightful tide of national comics $[\mathrm{N}]$. Jiangxi Daily, 2020-10-15(008).

[6] Gao Zhongwen. Monkey King: Hero Is Back: national comics are recovering. Douban Literature, 2018 